\title{
Microbial community structure across grazing treatments and environmental gradients in the Serengeti
}

\author{
Bo Maxwell Stevens ${ }^{1,{ }^{*}}$, Derek Lee Sonderegger ${ }^{2}$, Nancy Collins Johnson ${ }^{1,3}$ \\ 1 School of Earth and Sustainability, Northern Arizona University, Flagstaff, AZ 86011, USA \\ 2 Department of Mathematics and Statistics, Northern Arizona University, Flagstaff, AZ 86001, USA \\ 3 Department of Biological Sciences, Northern Arizona University, Flagstaff, AZ 86011, USA
}

H I G H L I G H T S

- Volcanic inputs and grazing impact the distribution of microbes in Serengeti soil.

- Soil texture and phosphorus are important environmental filters structuring soil microbes.

- Herbivores impact microbial communities via environmental filtering not stochastic dispersal.

\section{GRAPHICAL ABSTRACT}

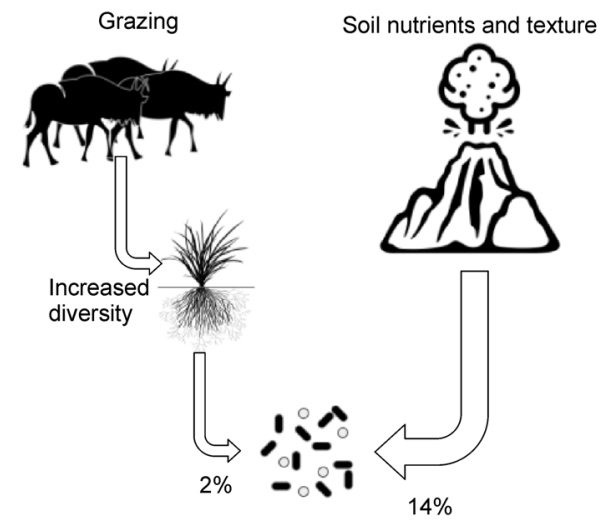

\section{ARTICLE INFO}

Article history:

Received June 1, 2020

Revised September 11, 2020

Accepted September 21, 2020

Keywords:

Soil bacteria

Community ecology

Grazing

Serengeti National Park

Soil texture

Phosphorus

\section{A B S T R A C T}

As one of the last remaining naturally grazed ecosystems on Earth, the Serengeti National Park is an ideal location to study the influence of migratory mammals on the structure of microbial communities and the factors that generate biogeography of soil microbes. Furthermore, volcanic inputs generate environmental gradients that may also structure microbial communities. We studied 16S rRNA amplicons in a 13-year herbivore removal experiment to examine the influence of grazing and environmental gradients on the natural distribution of soil microbes. Removal of mammalian herbivores shifted microbial community structure, with 31 taxa that were significant indicator taxa of the ungrazed treatment and three taxa that were indicators of the grazed treatment. The abundance of many taxa were correlated with soil texture, phosphorus, iron, calcium and rainfall, and the evenness of taxa within samples was also correlated with these variables. Bayesian general linear mixed effects models with single predictors of multiple, highly correlated variables of beta diversity were consistent with a significant, but weak $(2 \%)$, effect of grazing, and stronger effects of phosphorus (14\%). Beta diversity of microbial communities was greater in grazed than in ungrazed plots; suggesting that the impacts of grazing on community assembly of microbes results from deterministic environmental filtering caused by the influence of herbivores on plant communities and soil properties rather than stochastic dispersal via herds of large mammals. These herbivore effects are superimposed on deterministic environmental filtering by natural soil and precipitation gradients across the Serengeti.

() Higher Education Press 2020

* Corresponding author

E-mail address: bo_stevens@nau.edu (B.M. Stevens) 


\section{Introduction}

Soil bacteria and archaea serve critical functions in ecosystems but little is known about the factors that control their distribution in natural landscapes. Analyzing the biogeography of bacteria and archaea (hereafter referred to as microbes) and determining the underlying mechanisms affecting their distribution will help elucidate the responses of these important soil organisms to disturbance and environmental factors. Deterministic and stochastic mechanisms may influence the biogeography of soil microbes (Hanson et al., 2012). Environmental filtering is a deterministic mechanism by which various factors contribute to community assembly and species diversity (Martiny et al., 2006). Many environmental factors can be used to predict the distribution and diversity of microbial communities within the soil (Fierer, 2017). On the other hand, stochastic processes like dispersal may influence community assembly at regional scales (Martiny et al., 2006). The Serengeti National Park in Tanzania provides an ideal location to investigate the relative effects of environmental filters (deterministic niche model) and passive dispersal (stochastic null model) on microbial communities. The purpose of this study is to examine the relative importance of dispersal by large animals and environmental filters on the biogeography of soil microbes in the Serengeti. To accomplish this, we examined the diversity and distribution of microbial communities in a replicated experiment that removed large mammalian herbivores for 13 years that is superimposed on natural gradients of abiotic conditions.

Soil microbes exist within a complex web of organisms that include large grazing animals with many potential mechanisms for affecting microbial communities. The Serengeti hosts one of the largest natural grazing ecosystems in the world with currently over two million large mammalian herbivores (Eby et al., 2014). Moderate levels of grazing can alter soil nutrient concentrations by transporting nutrients and modifying plant communities (Anderson et al., 2007). In ecosystems with high soil fertility where nutrient cycling is dominated by bacteria, grazing may have a positive effect on decomposer bacteria (Bardgett and Wardle, 2003). In addition to the direct effects of urine and dung on soil biota (McNaughton et al., 1997; Bardgett et al., 1998), grazing can indirectly influence microbial diversity by impacting plant community composition and also through stimulating net primary productivity and aboveground biomass (McNaughton, 1979, 1985), leading to increased photosynthesis and root exudation (Bardgett et al., 1998). Comparison of soil microbes between grazed and ungrazed treatments in a long-term field experiment will help elucidate the relative importance of deterministic animalgenerated environmental filters combined with stochastic passive dispersal by the animals.

In the Serengeti, local topography and volcanic inputs have created inverse gradients of soil properties and precipitation (G. D. Anderson and Talbot, 1965; Ashley et al., 2014). Active volcanoes to the east continue to influence soil properties with eruptions as recent as 2008 (Sinclair and Arcese, 1995; Vaughan et al., 2008). Ash deposits from the nearby Ngorongoro Volcanic Highlands create gradients of soil texture, calcium, iron, phosphorus and $\mathrm{pH}$ (Anderson and Talbot, 1965; Ruess and Seagle, 1994; Ashley et al., 2014). Many studies have found that $\mathrm{pH}$ is a significant driver of microbial community composition globally (Fierer and Jackson, 2006; Lauber et al., 2009; Griffiths et al., 2011; Kaiser et al., 2016). Phosphorus availability is linked to soil pH, calcium, and iron because of chemical interactions on soil particles. Phosphorus availability is highest in neutral $\mathrm{pH}$ ranges, calcium immobilizes it at higher $\mathrm{pH}$ ranges (Schachtman et al., 1998; Brady and Weil, 2017), and iron immobilizes it at lower $\mathrm{pH}$ ranges, and this indirectly affects the growth of microbes and plants (Pigna and Violante, 2003; Vance et al., 2003). Increasing phosphorus availability can influence microbial community composition and diversity (Beauregard et al., 2009; Kuramae et al., 2011, 2012; Tan et al., 2012). Deterministic environmental filters like soil characteristics directly affect microbial communities by influencing resource availability and habitat structure, and they indirectly affect bacterial communities by influencing biotic factors such as vegetation and food webs.

Although no single factor consistently explains the biogeography of soil microbes, certain disturbances and environmental variables may correspond with spatial patterns in their composition and abundance. We compared microbial communities inside and outside grazing exclosures to test the alternative hypotheses that microbial communities are structured by stochastic dispersal by large mammalian herbivores versus deterministic effects of herbivory on plant and soil properties. Also, we tested the deterministic effects of gradients in precipitation, soil organic matter, $\mathrm{pH}$, nitrogen, phosphorus, calcium, iron and texture on the structure of soil microbial communities. The goal of this study is to increase our understanding of the biogeography of soil microbes in a naturally grazed, tropical grassland. Evidence of deterministic niche differentiation will help inform the development of models of microbial assembly that may link community structure with ecosystem functions.

\section{Methods}

\subsection{Sites}

In 1999, a herbivore removal experiment was installed at eight sites within the Serengeti National Park, Tanzania (Fig. 1; Table S1; Anderson et al., 2007). Six plots (4 $\mathrm{m} \times 4 \mathrm{~m})$ were established at each site with three randomly assigned plots open to grazing and the other three plots with $2 \mathrm{~m}$ tall chainlinked fences to exclude grazing by large animals including wildebeest, zebras, Thomson's gazelles, buffalo, and topi (McNaughton, 1985; Anderson et al., 2007). Theft of all the fences at one site in the eastern corridor prevented its inclusion in this study. Soil samples were collected from the 
remaining seven sites during the rainy season in May, 2012. Precipitation in the Serengeti National Park in 2012 was lowest in the southern $(662 \mathrm{~mm})$ and highest in the northern sites (1143 mm; Table 1).

\subsection{Soil analyses}

Soil samples were collected from holes (approximately $20 \mathrm{~cm}$ deep) created by excavating grasses at all seven sites ( $n=42)$. Within six hours of collection, soils were dried for $48 \mathrm{~h}$ in a solar drier. After 2 weeks, the dry samples were brought to the laboratory and frozen for long-term storage. Frozen soil samples were dried at $103^{\circ} \mathrm{C}$ and sieved $(<2$ $\mathrm{mm}$ ). Soil organic matter was measured using loss on ignition, $2 \mathrm{~g}$ subsamples were weighed, heated to $550^{\circ} \mathrm{C}$ for $24 \mathrm{~h}$ in a Lindberg HB muffle furnace (Lindberg/MPH, Riverside, MI 49084) then reweighed (Heiri et al., 2001). Soil pH was measured potentiometrically in a 1:2.5 water:soil paste at the Soil Science Laboratory of Sokoine University of Agriculture in Morogoro, Tanzania (Klute, 1986). To measure total phosphorus, calcium, and iron concentrations, $0.3 \mathrm{~g}$ subsamples were ground and digested in $7 \mathrm{~mL}$ concentrated nitric acid and $3 \mathrm{~mL} \mathrm{30 \%} \mathrm{hydrogen} \mathrm{peroxide} \mathrm{in} \mathrm{Milestone} 900$ Microwave Digestor (Ethos Inc., Bristol, UK). Samples were digested for $20 \mathrm{~min}$ and reached a maximum temperature of $425^{\circ} \mathrm{C}$. Total soil phosphorus concentration converted to orthophosphate was quantified via colorimetry (Grimshaw, 1987) on a QuikChem 8000 Series FIA + (Lachat Instruments, Milwaukee, WI 53218) using QuikChem Method 10-115-01-1-A. Total iron and calcium were measured on an AAnalyst 100 Atomic Absorption Spectrophotometer (Perkin Elmer, Waltham, MA

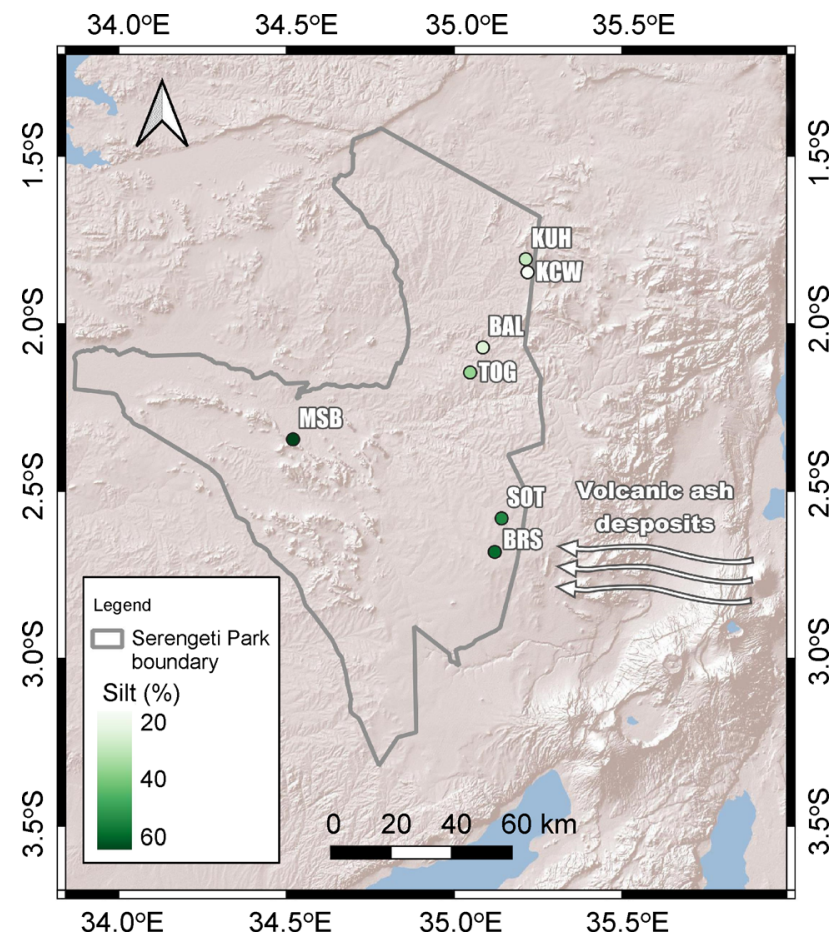

Fig. 1 Locations of the seven study sites within the Serengeti National Park, Tanzania: Balatines (BAL), Barafu (BRS), Klein's Camp West (KCW), Kuku Hills (KUH), Soit le Motonyi (SOT), Togora (TOG), and Musabi Plains (MSB). The gradient in soil texture is illustrated in green, darker color indicates higher percent silt.

Table 1 Annual precipitation (AP), and edaphic properties of the seven study sites in the Serengeti National Park, Tanzania.

\begin{tabular}{|c|c|c|c|c|c|c|c|}
\hline Sites & Site code & $\mathrm{AP}(\mathrm{mm})$ & $\mathrm{pH}$ & Bulk density $\left(\mathrm{g} \mathrm{cm}^{-3}\right)$ & Total $\mathrm{N}\left(\mathrm{mg} \mathrm{cm}^{-3}\right)$ & Total P $\left(\mathrm{mg} \mathrm{cm}^{-3}\right)$ & SOM $(\%)$ \\
\hline Barafu & BRS & 662 & $7.6 \mathrm{a}$ & $1.1 \mathrm{~b}$ & $2.8 \mathrm{a}$ & $6.1 \mathrm{a}$ & $16.2 \mathrm{a}$ \\
\hline Soit le Motonyi & SOT & 662 & $7.8 \mathrm{a}$ & $1.0 \mathrm{~b}$ & $1.1 \mathrm{~b}$ & $4.8 \mathrm{~b}$ & $11.8 \mathrm{bc}$ \\
\hline Togora Plains & TOG & 851 & $6.4 \mathrm{bc}$ & $1.4 \mathrm{a}$ & $2.0 \mathrm{ab}$ & $1.2 \mathrm{~d}$ & $7.2 \mathrm{bcd}$ \\
\hline Balanites & BAL & 851 & $6.7 \mathrm{bc}$ & $1.4 \mathrm{a}$ & $2.7 \mathrm{a}$ & $0.7 \mathrm{de}$ & $6.9 \mathrm{~cd}$ \\
\hline Klein's Camp West & $\mathrm{KCW}$ & 1143 & $6.9 \mathrm{~b}$ & $1.3 \mathrm{a}$ & $2.8 \mathrm{a}$ & $0.1 \mathrm{e}$ & $10.2 \mathrm{~b}$ \\
\hline Kuku Hills & $\mathrm{KUH}$ & 1143 & $6.3 \mathrm{c}$ & $1.0 \mathrm{~b}$ & $1.3 a b$ & $0.1 \mathrm{e}$ & $7.8 \mathrm{~d}$ \\
\hline Musabi Plains & MSB & 1039 & $6.3 \mathrm{c}$ & $1.0 \mathrm{~b}$ & $1.5 \mathrm{ab}$ & $2.0 \mathrm{c}$ & $11.8 \mathrm{bc}$ \\
\hline Sites & Site code & Clay (\%) & Silt (\%) & Sand (\%) & Total $\mathrm{Ca}\left(\mathrm{mg} \mathrm{cm}^{-3}\right)$ & Total Fe $\left(\mathrm{mg} \mathrm{cm}^{-3}\right)$ & \\
\hline Barafu & BRS & $24.8 \mathrm{a}$ & $55.2 \mathrm{a}$ & $20.0 d$ & $20.2 \mathrm{a}$ & $24.0 \mathrm{a}$ & \\
\hline Soit le Motonyi & SOT & $24.9 \mathrm{a}$ & $51.8 \mathrm{a}$ & $23.3 \mathrm{~d}$ & $16.6 \mathrm{~b}$ & $18.3 \mathrm{~b}$ & \\
\hline Togora Plains & TOG & $12.8 \mathrm{~b}$ & $39.9 \mathrm{~b}$ & $47.3 \mathrm{c}$ & $3.5 \mathrm{c}$ & $9.4 \mathrm{c}$ & \\
\hline Balanites & BAL & $9.7 \mathrm{bc}$ & $30.4 \mathrm{~cd}$ & $59.9 a b$ & $2.6 \mathrm{c}$ & $8.3 \mathrm{~cd}$ & \\
\hline Klein's Camp West & $\mathrm{KCW}$ & $8.0 \mathrm{c}$ & $24.8 \mathrm{~d}$ & $67.2 \mathrm{a}$ & $2.7 \mathrm{c}$ & $8.0 \mathrm{~cd}$ & \\
\hline Kuku Hills & $\mathrm{KUH}$ & $10.4 \mathrm{bc}$ & $34.8 \mathrm{bc}$ & $54.9 \mathrm{bc}$ & $1.8 \mathrm{c}$ & $4.5 \mathrm{~d}$ & \\
\hline Musabi Plains & MSB & $22.5 \mathrm{a}$ & $58.7 \mathrm{a}$ & $18.8 \mathrm{~d}$ & $3.9 \mathrm{c}$ & $18.4 \mathrm{~b}$ & \\
\hline
\end{tabular}


02451). Samples were compared to in-house standards and external standards produced by Ricca Chemical Company (Arlington, TX 76012) and Hach Company (Loveland, CO 80539).

Soil texture was determined using laser diffraction particle size analysis (Beuselinck et al., 1998). Unsieved soil samples were suspended in water and analyzed on a LS 13320 Series Laser Diffraction Particle Size Analyzer (Beckman Coulter Brea CA 92821). Particle sizes were grouped according USDA soil texture classification. Our soil textural classification figure was generated from $\mathrm{R}$ code available online (Hamilton, 2014). Soil bulk density and total soil nitrogen concentrations were obtained from previous analyses from the same plots (Antoninka et al., 2015). Measurements of soil organic matter, total phosphorus, nitrogen, calcium, and iron were adjusted by bulk density.

\subsection{Molecular analysis}

Amplicons were produced in a two-step protocol (Berry et al., 2011). Samples were amplified in triplicate PCR reactions for the $16 \mathrm{~S}$ v4 region using the universal bacterial primers $515 \mathrm{~F}$ (5'-GTGCCAGCMGCCGCGGTAA-3') and 806R (5'-GGACTACHVGGGTWTCTAAT-3') (Bates et al., 2011). First round reactions were performed in triplicate in 384 well plates. The 8 $\mu \mathrm{L}$ volumes contained the following: $1 \mu \mathrm{M}$ each primer, 200 $\mu \mathrm{M}$ each dNTP (Phenix Research, Candler, NC), $0.01 \mathrm{U} / \mu \mathrm{L}$ Phusion HotStart II DNA Polymerase (Life Technologies), 1X HF Phusion Buffer (Life Technologies), $3 \mathrm{mM} \mathrm{MgCl}_{2}, 6 \%$ glycerol, and $1 \mu \mathrm{L}$ normalized template DNA. Cycling conditions were: $2 \mathrm{~min}$ at $95^{\circ} \mathrm{C}$ followed by 20 cycles of $30 \mathrm{~s}$ at $95^{\circ} \mathrm{C}, 30 \mathrm{~s}$ at $55^{\circ} \mathrm{C}, 4 \mathrm{~min}$ at $60^{\circ} \mathrm{C}$. Triplicate reactions for each sample were pooled by combining $4 \mu \mathrm{L}$ from each well, and $2 \mu \mathrm{L}$ was used to check for results on an agarose gel. The remainder was diluted 10 -fold and used as template in a second PCR reaction in which indexed tails (Caporaso et al., 2012) were added. Second round reaction conditions were identical to the first round except only one reaction was conducted per sample and only 15 total cycles were performed. Indexed PCR products were purified using carboxylated magnetic beads (Rohland and Reich, 2012), quantified by PicoGreen fluorescence, and an equal mass of each sample was combined into a final sample pool. The pool was purified and concentrated, and subsequently quantified by quantitative PCR against Illumina DNA Standards (Kapa Biosystems, Wilmington, MA). Sequencing was carried out on a MiSeq Desktop Sequencer (Illumina Inc, San Diego, CA) running in paired end $2 \times 150$ mode.

\subsection{Data analysis}

The forward reads of the $16 \mathrm{~S}$ amplicons were imported into QIIME 2 version 2018.11 (Bolyen et al., 2018). Demultiplexing was carried out using minimum quality threshold of q20 and default parameters in QIIME 2. Based on quality threshold, visualized with FastQC version 11.7, reads were trimmed to 139 bases (S. Andrews, 2010). To determine phylogenetic diversity metrics, a rooted phylogenetic tree was created with MAFFT sequence alignment and FastTree in QIIME 2. QIIME 1.9.1 was used to filter samples below $0.005 \%$ abundance (Caporaso et al., 2010; Bokulich et al., 2013). To remove singletons by sample, the OUT_picking_workflow.sh command in akutils v1.1.1 was performed (Andrews, 2018). Alpha and beta diversity metrics were performed with the q2diversity plugin for QIIME 2 using the core-metrics-phylogenetic command with a sampling depth of 45000 . We used Shannon diversity index to capture bacterial richness and evenness. To estimate alpha diversity with phylogenetic structure, we used Faith's phylogenetic diversity index (Faith, 1992). To separate community evenness, we used Pielou's evenness index, where values are constrained to 0 and 1, with higher values representing even abundance of community members. To generate figures, we used the scikitbio 0.2.3 (http://scikit-bio.org), matplotlib 3.1.0, and seaborn 0.9.0 python packages.

\subsection{Statistical analyses}

In an attempt to account for spatial autocorrelation, beta diversity of bacterial communities were analyzed with single regressions using custom random effects terms to account for spatial autocorrelation (Anderson et al., 2011) of Bayesian general linear mixed effects models using the "rstanarm" $R$ package version 2.17.4 (Stan Development Team, 2017). Weighted and unweighted UniFrac (Lozupone and Knight, 2005), and Bray-Curtis dissimilarity for all unique nonzero pairs of plots was the response variable $(n=861$ for each metric). Standardized values for distance between continuous environmental variables were used to predict beta diversity. Grazing treatment categories were created for all possible combinations of treatments (e.g. beta diversity of grazed vs. grazed, grazed vs. ungrazed, and ungrazed vs. ungrazed samples). Grazing treatments in the model are treated as dummy variables 0 and 1 . As per typical model behavior, null models are assigned by alphabetical order, hence grazed vs. grazed was the null model. We included a random effect for spatial autocorrelation that represented all unique alphabetized combinations of sites. Additionally, we used a random slope for each model.

Eleven predictor variables were analyzed separately; grazing treatment, soil organic matter (SOM), $\mathrm{pH}$, rainfall, percent sand, silt, and clay, and total concentrations of nitrogen, phosphorus, calcium, and iron. Rainfall for 2012 was as determined by satellite measurements from NASA's Global Precipitation Measurement mission (Hou et al., 2013). To estimate variation explained by each model, the 'bayes_R2' function in 'rstanarm' was used to calculate an $r$ squared (Stan Development Team, 2017). To determine the variation explained by the fixed effect (e.g., explained variation) of each model, the full model $r$-squared $\left(R^{2}\right.$ full) was partitioned into an $r$-squared for the fixed $\left(R^{2}\right.$ fixed) and random effect for unexplained variation ( $R^{2}$ random) by calculating the sum squared error for the full model and for a null model with random effects only. All models used three 
chains with default parameters (family $=$ Gaussian, prior $=$ normal, iterations $=2000$, adapt $=0.99)$, and all models converged (Rhat < 1.05).

To summarize overall patterns between bacterial community composition and abiotic factors, we used principal coordinate analysis (PCOA) and the Spearman's rank correlation coefficient in the BIOENV function from scikit-bio. To test the effect of abiotic characteristics on bacterial community composition, we used a distance-based redundancy analysis (db-RDA) (Legendre and Anderson, 1999) performed with forward and backward model selection using the 'capscale' and 'ordistep' functions in the vegan package version 2.5-4 (Oksanen et al., 2018). We performed the dbRDA analysis on Bray-Curtis dissimilarity with default parameters. Percent sand was removed from the selected db-RDA model post hoc because it did not contribute to the overall model. Indicator species analyses of amplicon sequence variants (ASVs, taxa) were used to determine which bacteria were associated with grazing treatments and sites using the 'multipatt' function in the 'indicspecies' package version 1.7.6 (de Cáceres and Legendre, 2009) package in R (version 3.3.0) with default values. Only ASVs with significant indicator species $(P<0.05)$ are reported. $P$-values were determined with 999 permutations. The square root of the indicator value (func = "IndVal.g") was used as the test statistic.

\section{Results}

\subsection{Soil characteristics}

Soil nutrient analyses indicated significant edaphic gradients created by the Ngorongoro Volcanic Highlands (Fig. 1; Table 1). As expected, soil throughout the southern Serengeti plains is enriched by volcanic deposits rich in phosphorus, iron, and calcium, with deposits gradually decreasing with increasing latitude. Soil phosphorus concentration was significantly higher in the southern site $\left(6.1 \mathrm{mg} \mathrm{cm}^{-3}\right)$ than the northern site $\left(0.1 \mathrm{mg} \mathrm{cm}^{-3}\right.$; Table 1$)$. Total soil nitrogen concentration was between 1.1 and $2.3\left(\mathrm{mg} \mathrm{cm}^{-3}\right)$ throughout the seven sites (Table 1). Soil organic matter ranged from $6.9 \%$ (BAL) to $16.2 \%$ (BRS; Table 1). Total calcium and iron concentrations were lowest in the northern site $\left(1.8\right.$ and $4.5 \mathrm{mg} \mathrm{cm}^{-3}$, respectively) and highest in the southern site (20.2 and 24.0 $\mathrm{mg} \mathrm{cm}{ }^{-3}$, respectively; Table 1$)$. Sites in the north were comprised of sandy loam soil with low phosphorus concentration while sites in the south were silty loam with high phosphorus concentration (Figs. 1, 2, Table 1). Because of the influence of volcanic ash, many of the environmental variables were highly correlated (Fig. S1). Notably, percent sand, silt, and clay were more than $90 \%$ correlated with each other and between $70 \%$ and $90 \%$ correlated with phosphorus concentration (Fig. S1).

\subsection{Community composition}

After read quality filtering, sequencing resulted in a total of
5702184 reads matching a total of 32372 ASVs. To remove potentially erroneous ASVs, we used a stringent table filtering threshold that removes singletons by sample and ASVs below $0.005 \%$ of total sequence abundance (Bokulich et al., 2013). ASV table quality filtering resulted in 4431104 (78.7\%) sequences matching 2782 ASVs (8.6\%). For all 42 samples, we had an average of 105502 sequences per sample, with a minimum of 52139 and maximum of 162093 sequences.

Microbial communities in this study were primarily dominated by Actinobacteria (19.5\%), Proteobacteria (19.5\%), and Acidobacteria (19.2\%). Other significant ( $>5 \%$ ) phyla included Verrucomicrobia (8.0\%), Firmicutes $(6.0 \%)$, Chloroflexi $(6.0 \%)$, and Planctomycetes $(5.5 \%)$. Phyla with $5 \%$ or less relative abundance comprised $16.2 \%$ of the overall abundance. Average relative abundances of microbial phyla for each site are reported in Fig. 3A. We used four different alpha diversity metrics to determine if environmental variables are related to richness and evenness (Fig. S2). We highlight the strong correlation between percent silt and evenness in Fig. $3 \mathrm{C}$ because it is a good proxy for volcanic ash input. Average Shannon diversity for each site ranged from $8.8( \pm 0.2)$ in BAL to $9.3( \pm 0.1)$ in BRS and was correlated positively with percent silt $\left(R^{2}=0.17\right)$ and total phosphorus concentration $\left(R^{2}=0.14\right)$. Overall, evenness was high throughout our study, ranging from $0.86( \pm 0.01)$ to $0.91( \pm 0.01)$. Evenness of communities was positively correlated with silt $\left(R^{2}=0.16\right)$, phosphorus $\left(R^{2}=0.25\right)$, and $\mathrm{pH}\left(R^{2}=0.11\right)$, and negatively correlated with rainfall $\left(R^{2}=0.33\right)$. Average Faith $\mathrm{PD}$, a phylogenetic diversity estimate, was lowest in BAL (61.2 \pm 14.3$)$ and highest in MSB $(82.1 \pm 6.0)$ and was not highly correlated with environmental variables. Similarly, richness as measured by the number of observed taxa, was lowest in BAL $(859 \pm 242.2)$ and highest in MSB (1253 \pm 156.2$)$ and was not correlated with environmental variables. Relative abundances of many of the 50 most common ASVs were strongly correlated with one or more environmental variables, mainly soil texture (Fig. 4, Table S2). Grazing had no effect on alpha diversity but had a subtle yet significant effect on beta diversity (Fig. 5, Table S4). Of the 12 strongest correlations, nine had positive and three had negative relationships with percent silt (Fig. S3, Table S2). Indicator species analysis of the grazing treatments revealed that all indicator ASVs were in the bacterial kingdom (Table S3), three ASVs were indicators of grazed plots and 31 were indicators of ungrazed plots (Fig. 3B, Table S3).

Phylogenetic (UniFrac) and non-phylogenetic (Bray-Curtis) metrics were similar across four highlighted environmental variables, phosphorus concentration, rainfall, percent silt, and $\mathrm{pH}$ (Fig. S4). Spearman correlations were much higher for percent silt (30.5 to 40.6\%; Fig. 3D, Fig S4), and low for $\mathrm{pH}$ (between $-7 \%$ and $-2.9 \%$; Fig. S4). Phosphorus concentration and rainfall are highly correlated with each other $(=-0.83$; Fig. S1), and spearman correlations were similar for both variables and all three beta diversity metrics (Fig. S4). Much of the dissimilarity of bacterial communities can be attributed to the presence or absence of ASVs, indicated by the similarities of unweighted UniFrac correlations and Bray-Curtis (Fig. S4). 


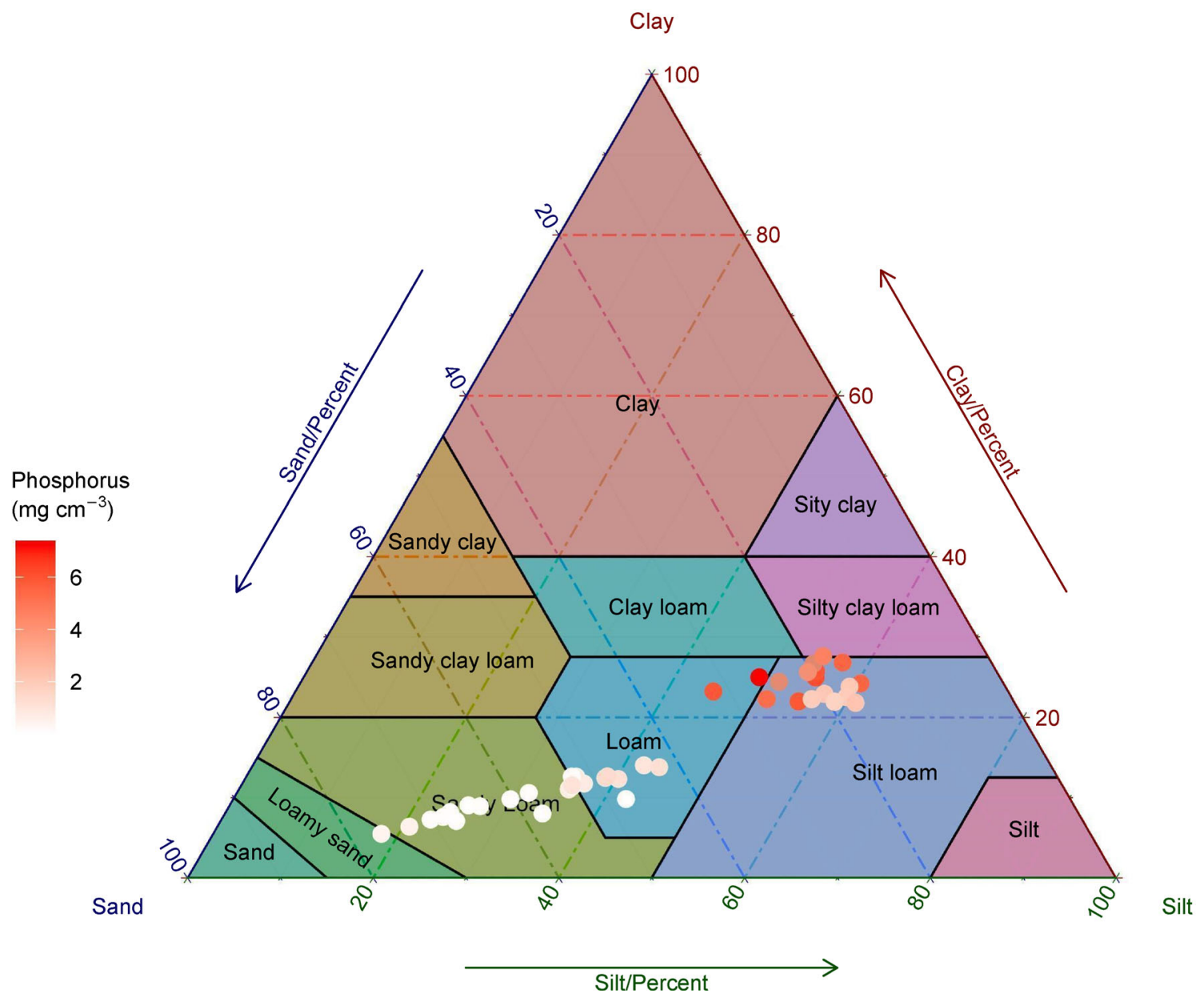

Fig. 2 Soil texture and phosphorus concentration of each plot at seven sites in this study. Plots are colored by soil phosphorus concentration, where darker red indicates fine-textured, high phosphorus soil that result from deposition of volcanic ash from highlands south of the Serengeti National Park.

In addition, we used a dbRDA to understand the effect of environmental variables on Bray-Curtis distances of bacterial communities. Model selection of dbRDA indicated that soil texture, rainfall, and phosphorus and iron concentration were important in explaining variation in bacterial community composition $(F=2.6, p<0.001$; Fig. S5). Overall, the dbRDA explained $16 \%$ of the variation in community composition (adjusted $R^{2}=0.164$ ).

\subsection{Linear mixed effects model}

The results of our Bayesian linear mixed effects models suggest that phosphorus and grazing are important in structuring microbial communities in the Serengeti. Model results are reported in Table S4 and visually represented in Fig. 5. Results for both weighted and unweighted UniFrac were remarkably similar to those of Bray-Curtis. Model results for the grazing treatment $(\mathrm{Cl}=[-0.07,-0.02])$ are consistent with an effect of grazing on beta diversity but grazing only explains $2 \%$ of the variation. The comparison of ungrazed with the null model (grazed) is negative (i.e., left of the zero line in
Fig. 5) which indicates that beta diversity is higher in grazed plots compared to ungrazed plots. Soil texture and phosphorus provided the best fit for determining the structure of bacterial communities. Here we are separating out the variation explained by the fixed effect (e.g., just the predictor variable of focus), rather than the random effects of the model as a whole. Percent clay, silt, and sand were three of the top four models. Total phosphorus concentration ranked among the top three variable on our list of models and had a positive slope which explained $14 \%$ of the variation in beta diversity, the $95 \%$ credible interval for phosphorus concentration in relation to beta diversity slightly overlapped zero $(\mathrm{Cl}=[0.00$, 0.53]), however, the mean of the posterior distribution (0.27) was the largest and was consistent with an effect, which may indicate that a large portion of the bacterial community structure is determined by levels of this important nutrient. Beta diversity values $(y)$ range between 0.19 and 0.85 , and standardized coefficients $(x)$ ranged from 0 to approximately 3. Therefore, a mean posterior distribution for a coefficient with a value of 0.27 (phosphorus) would indicate that for every 1 unit of change in the standardized $x$-value, beta diversity 

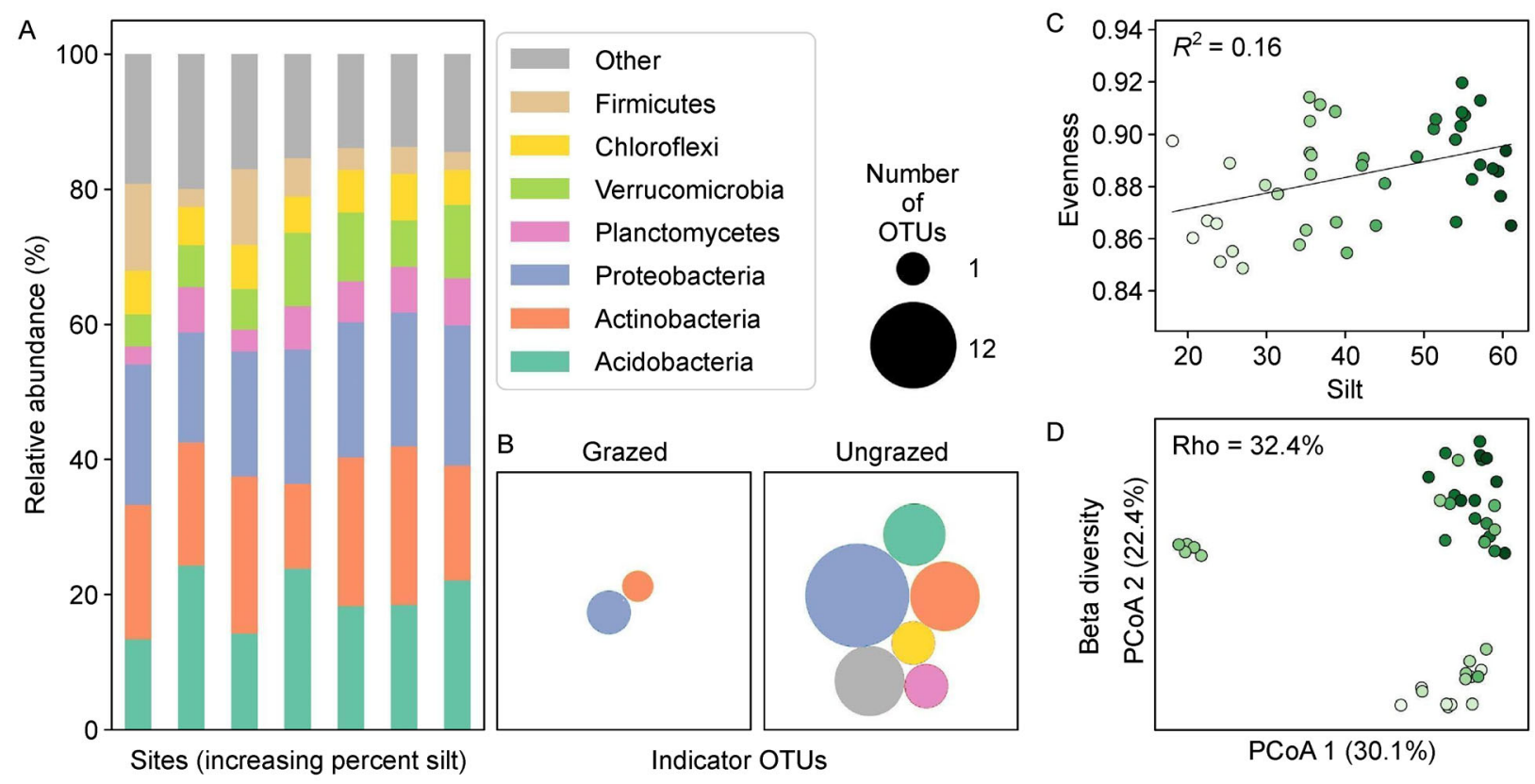

Fig. 3 Illustrations of microbial community structure across environmental gradients and grazing treatments in the Serengeti. (A) Relative abundance of bacterial phyla across the seven sites. (B) Visualization of indicator species grouped by phyla, indicated by colors. Area of each circle represents the number of indicator taxa within each phylum. (C) Correlation between Pielou's evenness, where 1 is completely even community and 0 in uneven. Points are colored by percent silt, darker colors are higher values, to facilitate interpretation. (D) beta diversity as determined by Bray-Curtis dissimilarity. Spearman's rho value is reported to illustrate the correlation between beta diversity and percent silt (green gradient).

increases by 0.27 , a large difference considering the range of possible values. Linear mixed models with other environmental variables produced fixed effect correlations near zero.

\section{Discussion}

Because the Serengeti National Park is a relatively undisturbed grassland, we can assume that the soil microbes observed in this study represent a long-term, stable community, notwithstanding seasonal fluctuations. Furthermore, microbial populations likely reflect interactions with the macrofauna through reciprocal upward and downward trophic cascades (Anderson et al., 2007; Sinclair et al., 2010; Stevens et al., 2018). Our results show that grazing by large, migratory mammals impacts microbial communities within the topsoil and reveal the importance of soil texture and mineral content in structuring communities.

\subsection{Large mammals leave a fingerprint on microbial communities}

Life in Serengeti soil evolved to co-exist beneath one of the largest mammalian migrations on Earth. We hypothesized that exclusion of large herbivores affects soil microbial communities and our linear mixed model results are consistent with that prediction (Figs. 3B, 5, Table S4). Millions of migratory mammals offer soil microbes dispersal opportunities resulting in more homogenous communities (Vos et al., 2013), however, our results indicate that mammalian vectors are not important in structuring microbial communities. If stochastic dispersal by large migratory mammals significantly influenced microbial communities, then beta diversity should be lower in the grazed plots compared to the ungrazed plots, but we observed the opposite result. Thus, we can reject the hypothesis that stochastic dispersal by mammalian herbivores structures microbial communities, but we cannot reject the hypothesis that grazing causes significant environmental filtering.

There are many potential mechanisms by which large grazing mammals might influence soil microbial communities (Bardgett et al., 1998). The influx of nutrients from mammalian waste products could cause a shift in bacterial communities, increasing community differences between grazed plots, especially at larger spatial distances, while ungrazed plots maintain higher similarity, as our data implies (Fig. 5, Tables S3 and S4). Furthermore, reduced plant species richness and shifts in the composition of plant communities that occur when grazers are excluded from the experimental plots (Anderson et al., 2007) could account for the lower beta diversity inside the fences compared to the unfenced, grazed plots. This interpretation is supported by the findings of a global-scale study that shows a correlation between the beta diversity of communities of plants and soil microbes (Prober et al. 2015).

Indicator species analysis revealed three indicators of grazing, including one taxa within Rhizobiaceae (Table S3), which is well known for taxa that fix nitrogen within plant roots (Spaink et al., 2012). Plant symbioses with Rhizobia within grazed plots could indicate a plant strategy to compensate for 


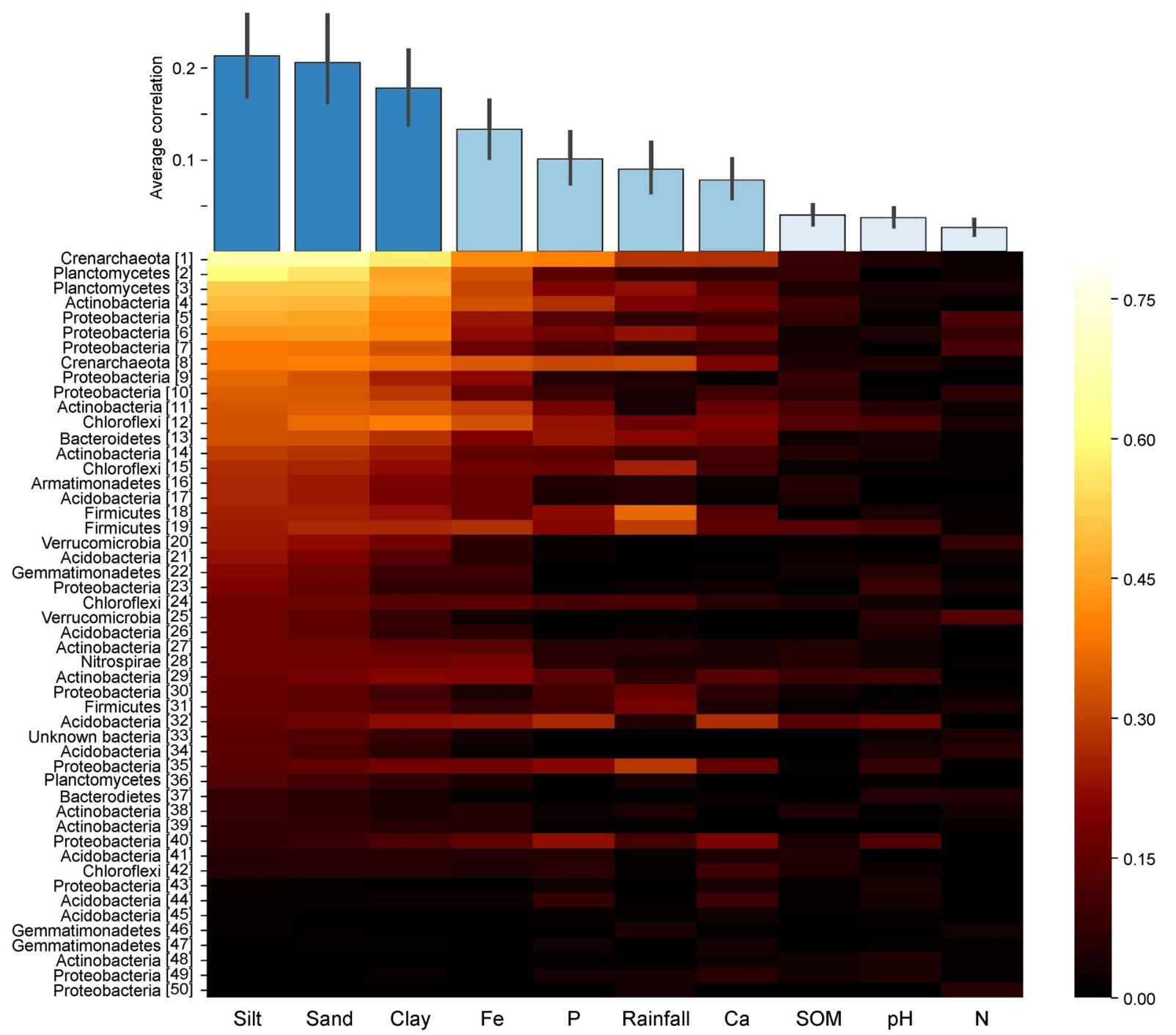

Fig. 4 Correlation values for comparisons of relative abundance of 16S rRNA for individual amplicon sequence variants (ASV) and abiotic variables. Phyla for the 50 most abundant ASVs are displayed on the $y$-axis. The top-left most value is the highest correlation, and values are sorted into descending order for each abiotic variable and ASV. Blue bars above the heatmap represent the average correlation, with a $95 \%$ confidence interval, for each environmental variable. Blue shades are used to emphasize visual differences and do not represent a statistical difference.

aboveground herbivory (Ramula et al., 2019). We found 31 indicator taxa in ungrazed plots, 10 times more than in grazed plots (Fig. 3B, Table S3). This indicates that removal of grazing increased homogeneity of the microbial communities and increased the abundance of particular microbial taxa. This could be linked to the drop in plant diversity, or the removal of inputs of dung and urine. Also, arbuscular mycorrhizal fungi can influence the community structure of soil bacteria (Artursson et al., 2006), and the abundance of these fungi has been shown to be higher inside the fences that exclude herbivores and also in the southern sites with fine textured soil and higher phosphorus content (Antoninka et al., 2015; Stevens et al., 2018, 2020). Future research is needed to understand the mechanisms of the grazing effect and link the mammalian microbiome with the soil microbiome using a timeseries of sampling that coordinates with the grazing cycle in the Serengeti.

\subsection{Volcanic inputs contribute to microbial community assembly}

Our results indicate that environmental gradients resulting from volcanic inputs of ash influence the biogeography of microbes in the Serengeti, but it is impossible to uncouple the interconnected soil factors that arise from the volcanic deposits. Soil texture explained $17 \%$ of the variation but was inconsistent with an effect on beta diversity (Table S4, Fig. 5), even with a strong gradient in soil texture (from $25 \%$ to almost 


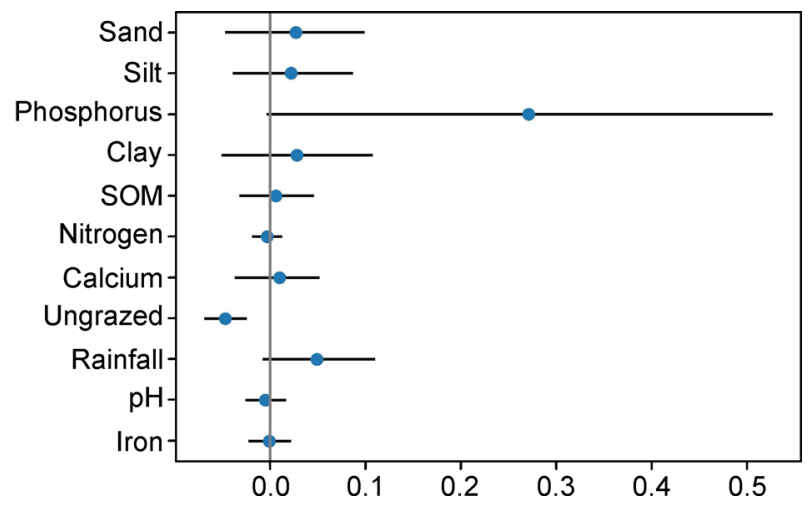

Fig. 5 Visualization of means and credible intervals for data reported in Table S4. The mean and 95\% credible interval for the posterior distribution of each Bayesian linear mixed effect model are reported. Models are ranked in order of increasing leave-on-out information criterion value, which is similar to Akaike's information criterion, in that smaller values indicate a better model fit. The $x$-axis represents coefficients for each scaled and centered variables. A negative value indicates lower difference in beta diversity, i.e. communities are more similar than to the null model (grazed plots).

$60 \%$ silt). Phosphorus concentration, on the other hand, explained $14 \%$ of the variation in community composition and was consistent with a strong effect on beta diversity (Table S4; Fig. 5). Therefore, it is likely that both phosphorus concentration and soil texture directly and indirectly (through biotic interactions) influence microbial community structure. Results from our mixed models indicate that further research is necessary to completely disentangle the effects of soil texture and phosphorus concentration. An experimental design created to separate mineralogy from soil texture could help separate these effects.

For organisms living at the scale of soil particles, the size and manner in which those soil particles coalesce can have a profound influence. Many studies have reported a connection between soil particle size and microbial diversity (Sessitsch et al., 2001; Carson et al., 2010; Chau et al., 2011; Neumann et al., 2013). Sand has larger pores with higher connectivity and therefore retains less water and nutrients than finer textured soil. The strong relationship between microbial community structure and soil texture could be linked to water potential, soil moisture, pore connectivity, and nutrient diffusion, rather than the texture itself (Saxton and Rawls, 2006; Dechesne et al., 2008; Carson et al., 2010; Neumann et al., 2013; Serna-Chavez et al., 2013). A previous study found microbial abundance to be positively correlated with water holding capacity and soil moisture in finer textured soil in the Serengeti (Ruess and Seagle, 1994). Small soil pores in fine textured soils may provide microbes a refuge from predation by bacterivorous protozoa and nematodes; and thus, loss through predation is likely to be higher in wetter, coarser soils that enable motility (Hassink et al., 1993; Nielsen et al., 2014). Furthermore, highly connected water-filled pores may favor competitive interactions (Treves et al., 2003). Models of two bacterial species indicate less coexistence in wet soil conditions because connectivity facilitates interactions among microbes such that highly competitive species can more easily exclude poor competitors in saturated soil compared to dry soil (Hardin, 1960; Dechesne et al., 2008; Long and Or, 2009). Overall, the structure of microbial communities in the Serengeti likely reflect both the top-down biotic influences of predation and bottom-up abiotic factors.

Many studies have found that soil $\mathrm{pH}$ is a significant driver of bacterial diversity (Fierer and Jackson, 2006; Lauber et al., 2009; Griffiths et al., 2011; Kaiser et al., 2016); but we observed $\mathrm{pH}$ had little relationship with the soil microbes in the Serengeti (Figs. 4, 5, S2-S5, Table S4). A likely reason why our results are not consistent with the literature is that the neutral soil $\mathrm{pH}$ range (6.3 to 7.8) observed in this study is ideal for microbial diversity, as opposed to the larger range of $\mathrm{pH}$ (3-9) captured globally (Fierer and Jackson, 2006). Furthermore, in contrast to a global analysis showing relationships between soil microbial communities and organic matter and nitrogen availability (Fierer, 2017), our study showed no relationship between microbial diversity and these soil variables (Figs. 4, 5, and S5, Table S4).

\subsection{Conclusion}

Much of the biogeography of microbial communities remains a mystery, but our study provides some insights into the distribution of soil microbes in a naturally grazed grassland. We discovered that removal of mammalian herbivores reduced the beta diversity of microbial communities, and this was likely caused by deterministic environmental filtering, such as changes in the diversity and composition of plant communities, rather than by stochastic dispersal by large mammals. Additionally, this study highlights the importance of soil properties, and especially texture and phosphorus in structuring microbial communities. Together, these results may help inform models of the regional biogeography of bacteria and archaea in natural, tropical grassland ecosystems. Future studies will benefit from a deeper understanding of microbial functional diversity and the spatial and temporal dynamics of life in the Serengeti soil.

\section{Acknowledgments}

The authors thank Emilian Mayemba for his help collecting samples and Michael Anderson, Mark Ritchie, Jeffrey Propster, Anita Antoninka and Daniel Revillini for their advice and input. We also thank Gustavo Zimmer for help with DNA extractions, and Lela Andrews and the NAU Environmental Genetics and Genomics Laboratory (EnGGen), Northern Arizona University, Flagstaff, AZ (nau.edu/enggen) for help with sequencing. Thanks to Emery Cowan for her contribution to the efficacy of science communication, and thanks to two anonymous reviewers for their insightful suggestions. The National Science Foundation pro- 
vided funding for this work to Nancy Collins Johnson (DEB0842327). This research was partially supported by the Microbial Ecology Collaborative with funding from NSF award \#EPS1655726.

\section{Data availability statement}

Our environmental data, correlation matrix, and ASV table are made publicly available on Dryad Digital Repository (https://doi. org/10.5061/dryad.hhmgqnkf6), and the sequences are be archived in the NCBI Sequence Read Archive (BioProject ID: PRJNA662920).

\section{Author contribution}

The research interests of BMS and NCJ focus on the microbial communities within soil, and particularly the distribution, abundance, function, and biogeography of bacteria and mycorrhizal fungi. DLS is a statistician with an interest in ecology. NCJ planned, designed the research, and collected samples. BMS performed bioinformatics, statistical analyses, and created figures. DLS and BMS created and analyzed linear models. BMS analyzed and, with the help of NCJ, interpreted data. BMS created figures and wrote the first draft of the manuscript. NCJ edited the final version.

\section{References}

Anderson, G.D., Talbot, L.M., 1965. Soil factors affecting the distribution of the grassland types and their utilization by wild animals on the Serengeti plains, Tanganyika. Journal of Ecology 53, 33-56.

Anderson, M.J., Crist, T.O., Chase, J.M., Vellend, M., Inouye, B.D., Freestone, A.L., Sanders, N.J., Cornell, H.V., Comita, L.S., Davies, K.F., Harrison, S.P., Kraft, N.J.B., Stegen, J.C., Swenson, N.G., 2011. Navigating the multiple meanings of $\beta$ diversity: A roadmap for the practicing ecologist. Ecology Letters 14, 19-28.

Anderson, T.M., Ritchie, M.E., McNaughton, S.J., 2007. Rainfall and soils modify plant community response to grazing in Serengeti National Park. Ecology 88, 1191-1201.

Andrews, L. (2018). akutils-v1.2.4: Facilitating analyses of microbial communities through QIIME. Zenodo. 10.5281/zenodo.1205079

Andrews, S., (2010). FastQC: a quality control tool for high throughput sequence data. http://www.bioinformatics.babraham.ac.uk/projects/fastqc

Antoninka, A.J., Ritchie, M.E., Johnson, N.C., 2015. The hidden Serengeti-Mycorrhizal fungi respond to environmental gradients. Pedobiologia 58, 165-176.

Artursson, V., Finlay, R.D., Jansson, J.K., 2006. Interactions between arbuscular mycorrhizal fungi and bacteria and their potential for stimulating plant growth. Environmental Microbiology 8, 1-10.

Ashley, G.M., Beverly, E.J., Sikes, N.E., Driese, S.G., 2014. Paleosol diversity in the Olduvai Basin, Tanzania: Effects of geomorphology, parent material, depositional environment, and groundwater on soil development. Quaternary International 322-323, 66-77.
Bardgett, R.D., Wardle, D.A., 2003. Herbivore-mediated linkages between aboveground and belowground communities. Ecology 84, 2258-2268 .

Bardgett, R.D., Wardle, D.A., Yeates, G.W., 1998. Linking aboveground and below-ground interactions: How plant responses to foliar herbivory influence soil organisms. Soil Biology \& Biochemistry $30,1867-1878$.

Bates, S.T., Berg-Lyons, D., Caporaso, J.G., Walters, W.A., Knight, R., Fierer, N., 2011. Examining the global distribution of dominant archaeal populations in soil. ISME Journal 5, 908-917.

Beauregard, M.S., Hamel, C., Atul-Nayyar, St-Arnaud, M., 2009. Long-term phosphorus fertilization impacts soil fungal and bacterial diversity but not AM fungal community in Alfalfa. Microbial Ecology 59, 379-389.

Berry, D., Mahfoudh, K.B., Wagner, M., Loy, A., 2011. Barcoded primers used in multiplex amplicon pyrosequencing bias amplification. Applied and Environmental Microbiology 77, 7846-7849.

Beuselinck, L., Govers, G., Poesen, J., Degraer, G., Froyen, L., 1998. Grain-size analysis by laser diffractometry: Comparison with the sieve-pipette method. Catena 32, 193-208.

Bokulich, N.A., Subramanian, S., Faith, J.J., Gevers, D., Gordon, J.I., Knight, R., Mills, D.A., Caporaso, J.G., 2013. Quality-filtering vastly improves diversity estimates from Illumina amplicon sequencing. Nature Methods 10, 57-59.

Bolyen, E., Rideout, J. R., Dillon, M. R., Bokulich, N. A., Abnet, C., AlGhalith, G. A., Alexander, H., Alm, E. J., Arumugam, M., Asnicar, F., Bai, Y., Bisanz, J. E., Bittinger, K., Brejnrod, A., Brislawn, C. J., Brown, C. T., Callahan, B. J., Caraballo-Rodríguez, A. M., Chase, J., Caporaso, J. G. (2018). QIIME 2: Reproducible, interactive, scalable, and extensible microbiome data science (e27295v2). Peer J Inc. https://doi.org/10.7287/peerj.preprints.27295v2

Brady, N.C., Weil, R.R., 2017. The nature and properties of soil (15th ed.). Pearson.

Caporaso, J.G., Kuczynski, J., Stombaugh, J., Bittinger, K., Bushman, F.D., Costello, E.K., Fierer, N., Peña, A.G., Goodrich, J.K., Gordon, J.I., Huttley, G.A., Kelley, S.T., Knights, D., Koenig, J.E., Ley, R.E., Lozupone, C.A., McDonald, D., Muegge, B.D., Pirrung, M., Reeder, J., Sevinsky, J.R., Turnbaugh, P.J., Walters, W.A., Widmann, J., Yatsunenko, T., Zaneveld, J., Knight, R., 2010. QIIME allows analysis of high-throughput community sequencing data. Nature Methods 7, 335-336.

Caporaso, J.G., Lauber, C.L., Walters, W.A., Berg-Lyons, D., Huntley, J., Fierer, N., Owens, S.M., Betley, J., Fraser, L., Bauer, M., Gormley, N., Gilbert, J.A., Smith, G., Knight, R., 2012. Ultra-highthroughput microbial community analysis on the Illumina HiSeq and MiSeq platforms. ISME Journal 6, 1621-1624.

Carson, J.K., Gonzalez-Quiñones, V., Murphy, D.V., Hinz, C., Shaw, J. A., Gleeson, D.B., 2010. Low pore connectivity increases bacterial diversity in soil. Applied and Environmental Microbiology 76, 3936-3942.

Chau, J.F., Bagtzoglou, A.C., Willig, M.R., 2011. The effect of soil texture on richness and diversity of bacterial communities. Environmental Forensics 12, 333-341.

de Cáceres, M., Legendre, P., 2009. Associations between species and groups of sites: Indices and statistical inference. Ecology 90 , 3566-3574. 
Dechesne, A., Or, D., Smets, B.F., 2008. Limited diffusive fluxes of substrate facilitate coexistence of two competing bacterial strains. FEMS Microbiology Ecology 64, 1-8.

Eby, S.L., Anderson, T.M., Mayemba, E.P., Ritchie, M.E., 2014. The effect of fire on habitat selection of mammalian herbivores: The role of body size and vegetation characteristics. Journal of Animal Ecology 83, 1196-1205.

Faith, D.P., 1992. Conservation evaluation and phylogenetic diversity Biological Conservation 61, 1-10.

Fierer, N., 2017. Embracing the unknown: Disentangling the complexities of the soil microbiome. Nature Reviews. Microbiology 15 , 579-590.

Fierer, N., Jackson, R.B., 2006. The diversity and biogeography of soil bacterial communities. Proceedings of the National Academy of Sciences of the United States of America 103, 626-631.

Griffiths, R.I., Thomson, B.C., James, P., Bell, T., Bailey, M., Whiteley, A.S., 2011. The bacterial biogeography of British soils. Environmental Microbiology 13, 1642-1654.

Grimshaw, H.M., 1987. The determination of total phosphorus in soils by acid digestion. In Rowland A.P. Ed., Chemical analysis in environmental research. NERC/ITE. pp. 92-65

Hamilton, N., (2014, January 15). USDA Textural Soil Classification. R-Bloggers. https://www.r-bloggers.com/usda-textural-soil-classification/

Hanson, C.A., Fuhrman, J.A., Horner-Devine, M.C., Martiny, J.B.H., 2012. Beyond biogeographic patterns: Processes shaping the microbial landscape. Nature Reviews. Microbiology 10, 497-506.

Hardin, G., 1960. The competitive exclusion principle. Science 131 1292-1297.

Hassink, J., Bouwman, L.A., Zwart, K.B., Bloem, J., Brussaard, L., 1993. Relationships between soil texture, physical protection of organic matter, soil biota, and $\mathrm{C}$ and $\mathrm{N}$ mineralization in grassland soils. In: Brussaard, L., Kooistra, M.J., eds. Soil Structure/Soil Biota Interrelationships. Elsevier. pp. 105-128. https://doi.org/ 10.1016/B978-0-444-81490-6.50059-5

Heiri, O., Lotter, A.F., Lemcke, G., 2001. Loss on ignition as a method for estimating organic and carbonate content in sediments: Reproducibility and comparability of results. Journal of Paleolimnology 25, 101-110.

Hou, A.Y., Kakar, R.K., Neeck, S., Azarbarzin, A.A., Kummerow, C.D., Kojima, M., Oki, R., Nakamura, K., Iguchi, T., 2013. The global precipitation measurement mission. Bulletin of the American Meteorological Society 95, 701-722.

Kaiser, K., Wemheuer, B., Korolkow, V., Wemheuer, F., Nacke, H., Schöning, I., Schrumpf, M., Daniel, R., 2016. Driving forces of soil bacterial community structure, diversity, and function in temperate grasslands and forests. Scientific Reports 6, 33696.

Klute, A., 1986. Water retention: Laboratory methods. Methods of Soil Analysis: Part 1-Physical and Mineralogical Methods, SSSA book series(methodsofsoilan1), 635-662. https://doi.org/10.2136/ sssabookser5.1.2ed.c26

Kuramae, E.E., Gamper, H., van Veen, J., Kowalchuk, G., 2011. Soil and plant factors driving the community of soil-borne microorganisms across chronosequences of secondary succession of chalk grasslands with a neutral $\mathrm{pH}$. FEMS Microbiology Ecology 77 , 285-294.
Kuramae, E.E., Yergeau, E., Wong, L.C., Pijl, A.S., van Veen, J.A., Kowalchuk, G.A., 2012. Soil characteristics more strongly influence soil bacterial communities than land-use type. FEMS Microbiology Ecology 79, 12-24.

Lauber, C.L., Hamady, M., Knight, R., Fierer, N., 2009. Pyrosequencing-based assessment of soil $\mathrm{pH}$ as a predictor of soil bacterial community structure at the continental scale. Applied and Environmental Microbiology 75, 5111-5120.

Legendre, P., Anderson, M. J., 1999. Distance-Based Redundancy Analysis: Testing Multispecies Responses in Multifactorial Ecological Experiments. Ecological Monographs,69, 1-24.

Long, T., Or, D., 2009. Dynamics of microbial growth and coexistence on variably saturated rough surfaces. Microbial Ecology 58, 262275.

Lozupone, C., Knight, R., 2005. UniFrac: A new phylogenetic method for comparing microbial communities. Applied and Environmental Microbiology 71, 8228-8235.

Martiny, J.B.H., Bohannan, B.J.M., Brown, J.H., Colwell, R.K., Fuhrman, J.A., Green, J.L., Horner-Devine, M.C., Kane, M., Krumins, J.A., Kuske, C.R., Morin, P.J., Naeem, S., Øvreås, L., Reysenbach, A.L., Smith, V.H., Staley, J.T., 2006. Microbial biogeography: Putting microorganisms on the map. Nature Reviews Microbiology 4, 102-112.

McNaughton, S.J., 1979. Grazing as an optimization process: Grassungulate relationships in the Serengeti. American Naturalist 113, 691-703.

McNaughton, S.J., 1985. Ecology of a grazing ecosystem: The Serengeti. Ecological Monographs 55, 259-294.

McNaughton, S.J., Zuniga, G., McNaughton, M.M., Banyikwa, F.F., 1997. Ecosystem catalysis: Soil urease activity and grazing in the serengeti ecosystem. Oikos 80, 467-469.

Neumann, D., Heuer, A., Hemkemeyer, M., Martens, R., Tebbe, C.C., 2013. Response of microbial communities to long-term fertilization depends on their microhabitat. FEMS Microbiology Ecology 86, 71-84.

Nielsen, U.N., Ayres, E., Wall, D.H., Li, G., Bardgett, R.D., Wu, T., Garey, J.R., 2014. Global-scale patterns of assemblage structure of soil nematodes in relation to climate and ecosystem properties. Global Ecology and Biogeography 23, 968-978.

Oksanen, J., Blanchet, F., Friendly, M., Kindt, R., Legendre, P., McGlinn, D., Minchin, P., O'Hara, R., Simpson, G., Solymos, P., Stevens, M., 2018. Package 'vegan'. Community ecology package, R package version 2.5-4. Https://CRAN.R-project.org/package = vegan .

Pigna, M., Violante, A., 2003. Adsorption of sulfate and phosphate on andisols. Communications in Soil Science and Plant Analysis 34, 2099-2113.

Prober, S.M., Leff, J.W., Bates, S.T., Borer, E.T., Firn, J., Harpole, W. S., Lind, E.M., Seabloom, E.W., Adler, P.B., Bakker, J.D., Cleland, E.E., DeCrappeo, N.M., DeLorenze, E., Hagenah, N., Hautier, Y., Hofmockel, K.S., Kirkman, K.P., Knops, J.M.H., La Pierre, K.J., MacDougall, A.S., McCulley, R.L., Mitchell, C.E., Risch, A.C., Schuetz, M., Stevens, C.J., Williams, R.J., Fierer, N., 2015. Plant diversity predicts beta but not alpha diversity of soil microbes across grasslands worldwide. Ecology Letters 18, 85-95.

Ramula, S., Paige, K.N., Lennartsson, T., Tuomi, J., 2019. Over- 
compensation: A 30-year perspective. Ecology 100, e02667.

Rohland, N., Reich, D., 2012. Cost-effective, high-throughput DNA sequencing libraries for multiplexed target capture. Genome Research 22, 939-946.

Ruess, R.W., Seagle, S.W., 1994. Landscape patterns in soil microbial processes in the serengeti national park, tanzania. Ecology 75, 892-904.

Saxton, K.E., Rawls, W.J., 2006. Soil water characteristic estimates by texture and organic matter for hydrologic solutions. Soil Science Society of America Journal 70, 1569-1578.

Schachtman, D.P., Reid, R.J., Ayling, S.M., 1998. Phosphorus uptake by plants: From soil to cell. Plant Physiology 116, 447-453.

Serna-Chavez, H.M., Fierer, N.van Bodegom, P.M., , 2013. Global drivers and patterns of microbial abundance in soil. Global Ecology and Biogeography 22, 1162-1172.

Sessitsch, A., Weilharter, A., Gerzabek, M.H., Kirchmann, H., Kandeler, E., 2001. Microbial population structures in soil particle size fractions of a long-term fertilizer field experiment. Applied and Environmental Microbiology 67, 4215-4224.

Sinclair, A.R.E., Arcese, P., 1995. Serengeti II: Dynamics, Management, and Conservation of an Ecosystem. University of Chicago Press.

Sinclair, A.R.E., Metzger, K., Brashares, J.S., Nkwabi, A., Sharam, G., Fryxell, J.M., 2010. Trophic Cascades in African Savanna: Serengeti as a Case Study. In Terborgh, J., Estes, J. A., eds. Trophic Cascades: Predators, Prey and the Changing Dynamics of Nature. Island Press, Washington pp. 255-274.

Spaink, H.P., Kondorosi, A., Hooykaas, P.J.J., 2012. The Rhizobiaceae: Molecular Biology of Model Plant-associated Bacteria. Springer, Dordrecht.
Stan Development Team, 2017. RStanArm: Bayesian applied regression modelling via Stan (Version $\mathrm{R}$ package version 2.15.3) [Computer software]. http://mc-stan.org

Stevens, B.M., Propster, J., Wilson, G.W.T., Abraham, A., Ridenour, C., Doughty, C., Johnson, N.C., 2018. Mycorrhizal symbioses influence the trophic structure of the Serengeti. Journal of Ecology 106, 536-546.

Stevens, B.M., Propster, J.R., Öpik, M., Wilson, G.W.T., Alloway, S.L., Mayemba, E., Johnson, N.C., 2020. Arbuscular mycorrhizal fungi in roots and soil respond differently to biotic and abiotic factors in the Serengeti. Mycorrhiza 30, 79-95.

Tan, H., Barret, M., Mooij, M.J., Rice, O., Morrissey, J.P., Dobson, A., Griffiths, B., O'Gara, F., 2012. Long-term phosphorus fertilisation increased the diversity of the total bacterial community and the phoD phosphorus mineraliser group in pasture soils. Biology and Fertility of Soils $49,661-672$.

Treves, D.S., Xia, B., Zhou, J., Tiedje, J.M., 2003. A two-species test of the hypothesis that spatial isolation influences microbial diversity in soil. Microbial Ecology 45, 20-28.

Vance, C.P., Uhde-Stone, C., Allan, D.L., 2003. Phosphorus acquisition and use: Critical adaptations by plants for securing a nonrenewable resource. New Phytologist 157, 423-447

Vaughan, R.G., Kervyn, M., Realmuto, V., Abrams, M., Hook, S.J., 2008. Satellite measurements of recent volcanic activity at Oldoinyo Lengai, Tanzania. Journal of Volcanology and Geothermal Research 173, 196-206.

Vos, M., Wolf, A.B., Jennings, S.J., Kowalchuk, G.A., 2013. Microscale determinants of bacterial diversity in soil. FEMS Microbiology Reviews 37, 936-954. 